\title{
Berufsunfähigkeitsversicherung \\ Gibt es die auch für Personen über 60 Jahre?
}

Frage von Dr. H.-J. W.:

Ich hatte bis zum 60. Lebensjahr eine Berufsunfähigkeitsversicherung, welche nicht verlängert werden konnte. Gibt es eine sinnvolle Alternative (ich bin jetzt 62 Jahre alt) für den Fall der Fälle?

Antwort von D. Stroekens, Düsseldorf: Grundsätzlich ist es möglich, eine neue Berufsunfähigkeitsversicherung (BU) abzuschließen. Die Höhe der Beiträge hierzu hängt vom entsprechenden Eintrittsalter ab. Zudem wird eine Gesundheitsprüfung durchgeführt, mit der die Versicherungsgesellschaft prüft, ob sie das Risiko tragen will. Wenn keine besonderen gesundheitlichen Beeinträchtigungen bestehen, könnten Sie sich für weitere fünf Jahre bzw. bis zum Ruhestand mit einer BU absichern. Für niedergelassene Ärzte ist bei einer angenommenen Berufsunfähigkeitsrente von 1500 Euro im Monat mit einem monatlichen Beitrag von ca. 130 Euro zu rechnen. Bei angestellten Ärzten sollte sich der Beitrag auf ca. 100 Euro pro Monat belaufen.
Möglicherweise besteht auch die Option, die von Ihnen gewünschte Berufsunfähigkeitsversicherung in Verbindung mit der sogenannten Basisrente abzuschließen und so steuerliche Vergünstigungen in Anspruch zu nehmen. Hier ist es sinnvoll, dieses Thema

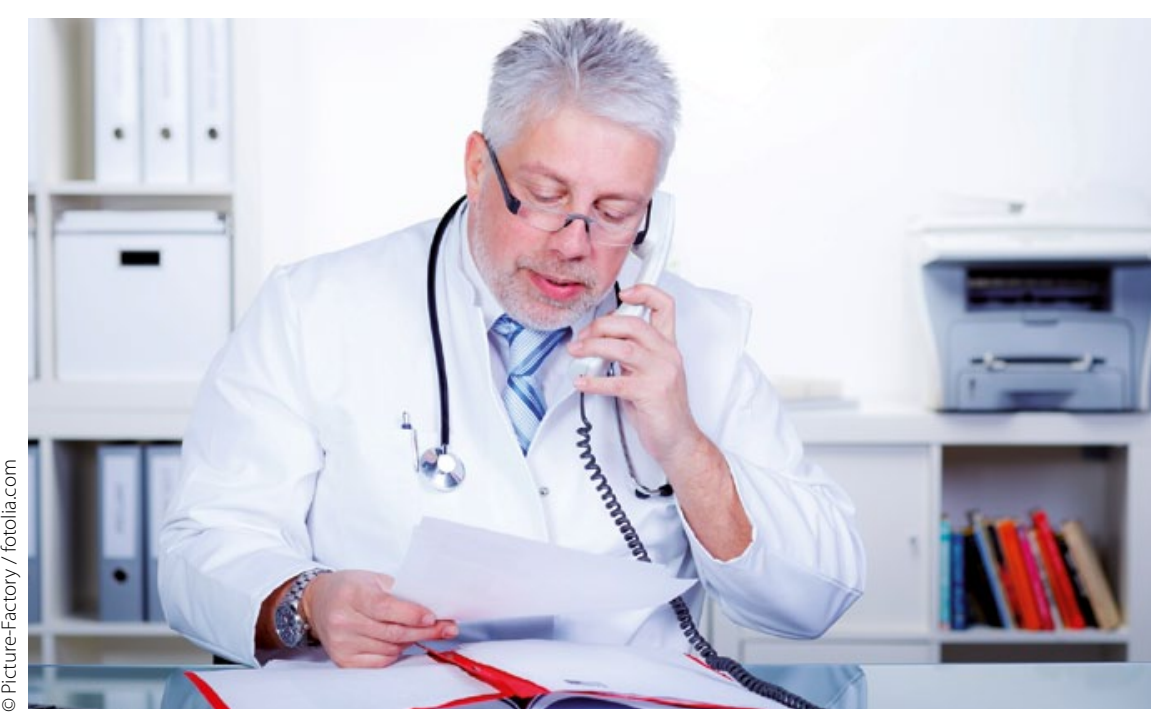

Auch jenseits der 60 kann man sich noch gegen Berufsunfähigkeit versichern. im persönlichen Gespräch mit Ihrem Bankberater zu klären.

- Dieter Stroekens, Deutsche Apotheker- und Ärztebank, Richard-Oskar-Mattern-Straße 6, D-40547 Düsseldorf

\section{Passagere Marcumarisierung}

\section{Warum muss ich das Antikoagulans langsam auschleichen?}

\section{Frage von Dr. R. U., Internist:}

Immer wieder wird z. B. von Angiologen nach einer passageren Marcumarisierung der Patienten (z. B. nach Lungenembolie) empfohlen, Marcumar langsam über zwei Wochen in der Dosis zu reduzieren, um es dann letztendlich ganz abzusetzen. Warum? Angenommen, ich hätte dann erneut das Phänomen der passageren $\mathrm{Hy}$ perkoagulabilität, dann müsste ich doch konsequenterweise auch erneut Heparin in therapeutischer Dosis gleichzeitig einsetzen, was nicht empfohlen wird. Kann ich Marcumar nicht von einem auf den anderen Tag absetzen?
Antwort von Dr. J. Kaufmann, Berlin: Phenprocoumon kann ohne vorangehende Dosisreduktion abgesetzt werden. Eine Normalisierung der Gerinnung tritt ca. 7-14 Tage nach Beendigung der Therapie ein. Das Phänomen der passageren Hyperkoagulabilität existiert bei Beendigung der Therapie nicht, da dieses durch den im Vergleich zu den Gerinnungsfaktoren II, IX und $X$ schnelleren Abfall der Gerinnungsinhibitoren Protein $C$ und $S$ bei Therapiebeginn bedingt ist. Das ist wiederum durch die längere Halbwertszeit der Gerinnungsfaktoren begründet (FII: 50 h, FIX: 24 h, FX: 36 h). Da die Therapiedauer, z. B. bei Lun- genarterienembolie, die Halbwertszeit der Gerinnungsfaktoren deutlich überschreitet, spielt die Halbwertszeit bei Beendigung der Therapie keine Rolle mehr.

- Dr. Jan Kaufmann, Deutsches Herzzentrum Berlin, Augustenburger Platz 1, D-13353 Berlin 